\title{
Effect of wheat bran and brown sugar on the yield of oyster mushroom (Pleurotus ostreatus)
} \author{
Muhammad Ali Khan ${ }^{1}$, Syed Hussain ${ }^{1}$, Fazal Said ${ }^{1}$, Habib Ullah \\ Khan $^{2}$ and Adil Hussain ${ }^{1 *}$ \\ 1. Department of Agriculture, Abdul Wali Khan University, Mardan, KP-Pakistan \\ 2. Department of Statistics, University of Malakand, Dir (Lower), KP-Pakistan \\ *Corresponding author's email: adilhussain@awkum.edu.pk
}

Muhammad Sajid ${ }^{1}$, Muhammad Imtiaz ${ }^{1}$, Fazal Jalal ${ }^{1}$, Badshah Islam ${ }^{1}$

Citation

Muhammad Sajid, Muhammad Imtiaz, Fazal Jalal, Badshah Islam, Muhammad Ali Khan, Syed Hussain, Fazal Said, Habib Ullah Khan and Adil Hussain. Effect of wheat bran and brown sugar on the yield of oyster mushroom (Pleurotus ostreatus). Pure and Applied Biology. Vol. 7, Issue 4, pp1186-1196.

http://dx.doi.org/10.19045/bspab.2018.700138

\begin{tabular}{llll}
\hline \hline Received: 27/04/2018 & Revised: 29/06/2018 & Accepted: 30/06/2018 & Online First: 30/08/2018 \\
\hline
\end{tabular}

\section{Abstract}

Mushrooms (toadstool) are the macroscopic, spore bearing, fleshy fruiting bodies of fungi usually produced above the surface of the substrate generally used as a food source. Among the different types of mushrooms found throughout the world, generally the name "Mushroom" is only associated with the button shaped mushrooms e.g. Agaricus bisporus. Mushroom has a huge basis of high value protein and other nutrients. Information about the medicinal value of mushrooms can be traced back to the 19th century and today it is considered as a very important food for humans because of its nutritional as well as medicinal value. In the present work, an experiment was performed to evaluate the effect of wheat brawn and brown sugar (Gur) on the yield of Oyster mushroom Pleurotus ostreatus. The data was recorded on days to half spawn running, days to spawn running completion, days to first picking, second picking, and third picking, number of pickings per treatment, and yield per picking. It was observed that high temperatures of more than $37^{\circ} \mathrm{C}$ had a negative effect on mushroom growth and as a result the spawn running and fruiting body production was significantly delayed. Results showed that average minimum number of days to half spawn running was recorded for the control, while an average minimum number of days to picking was recorded for the wheat bran with brown sugar (gur) solution, and maximum yield was recorded for wheat bran. Therefore, wheat bran is recommended for Pleurotus ostreatus cultivation. It is further recommended to test the effects of other different doses of wheat brawn and brown sugar on Pleurotus ostreatus yield and to test other sources of starch and sugar as supplements in the substrate.

Keywords: Brown sugar; Mushroom; Pleurotus ostreatus; Wheat bran

Introduction

Mushrooms are fungal fruiting bodies usually produced above the substrate surface and generally used as a food source (though not all mushroom species are edible). Among the different types of mushrooms found 
throughout the world, generally the name "Mushroom" is only associated with the button shaped mushroom technically called Agaricus bisporus. Besides these morphological features, there are gills at the underside of the cap which produce microscopic spores that serve as the seed of the fungus. Most mushroom species belong to the class Basidiomycetes of the division Basidiomycota of the kingdom Mycetae [1]. The identification of different mushroom species is especially difficult and requires basic understanding of their macroscopic structure and expertise about the nutrition. By far, many species of mushroom are highly poisonous and therefore, not edible [2]. One of the most common and easiest methods used for identification is the spore-print method. For this purpose, the mushroom cap is placed gill-side-down overnight. When the spores are released from the gills, they leave a powdery impression reflecting the shape of the gills. The shape and color of the powdery print or spore print is used to classify the mushroom species. Spore prints can vary in color from white to brown, purple, black, yellow, pink and other shades though dark shades of blue, red or green are very rare [3]. Mushroom has a huge basis of high value protein and other nutrients. Information about the medicinal value of mushrooms can be traced back to the 19th century and today it is considered as a very important food for humans because of its nutritional as well as medicinal value [4]. Consequently, the antimicrobial action of different polysaccharides from medicinal mushroom is widely acknowledged and most mushroom species are evaluated in terms of their medical efficiency [5]. Mushrooms based diet plays in important role in physiological attenuation of dietary fibers which plays an essential role in decreasing glucose level in blood, fat binding, and control of cholesterol levels provide good health [6].
Mushrooms as useful meal are used as nutrient dietary supplements to enhance immunity in the shape of capsules. Due to low starch content and occasional cholesterol, they are good supplements for diabetic and heart patients. It is estimated that $1 / 3$ portion of the total iron content of mushroom is in available form. Mushrooms are also used as anticancer drugs. Even they have been used to fight HIV efficaciously [7]. For the most part, immune-stimulation by restorative mushrooms happens by means of antigen-exhibiting cells (AEC) in the natural resistant framework comprising monocytes, macrophages and dendritic cells (DC). The cell reaction is activated by the identification of moderated microbial determined atoms, named pathogen-associated molecular patterns (PAMPs), by the PAMP-receptors [8]. The consumable Bacidiomycota mushroom Agaricus blazei develops normally in a region close to São Paulo, Brazil, where it has been utilized as a part of conventional solution against an assortment of maladies, including disease and malignancy [9]. Mushrooms are a standout amongst the most perishable items and have a tendency to lose quality, instantly after collection. Mostly mushrooms contain 90 percent of water and are therefore, highly perishable. However, their shelf life can be increased through post-harvest processing [10]. The short time-frame of realistic usability (1-3 days) is a disadvantage to the conveyance and advertising of this useful product [11]. Sustenance illumination shows up as a conceivable option for put away mushrooms, by uncovering sustenance to ionizing radiation, (for example, gamma or electron bar) with a specific end goal to upgrade its time span of usability and its wellbeing. Especially, gamma illumination has been shown to be a potential source for broadening the postharvest timeframe of realistic usability of crisp mushrooms [12]. Adjusted climate bundling modifies the 
typical creation of air to give an ideal air to diminishing the item breath rate, saving its quality and expanding its time span of usability. This can be latently accomplished inside a bundle subsequently of mushroom breath, devouring oxygen and creating chiefly carbon dioxide, and vaporous trade between the environments [13, 14]. The reduction in oxygen focus and increment in carbon dioxide fixation must not exceed a specific basic limit [15]. The absence of oxygen prompts anaerobic growth joined by off-scents because of the generation of unstable substances, for example, ethanol and acetaldehyde $[2,16]$. Cultivation of various mushroom species is though not a scientifically complex job. As described above, mushrooms have a very short shelf life primarily because they are one of the most fragile, palatable, and soft bodied food products and extremely sensitive to changes in temperature and moisture during their growth.

Various studies report the use of different substrates for growing mushrooms. Others have reported the effects of various nutrient supplements and changes in growth conditions on mushroom quality and yield. The impact of UV-C and UV-B light, wavelength 190-290 and 290-315 nm, individually, on the transformation of ergo sterol to vitamin D2 in a few palatable mushrooms has been studied. Results showed higher vitamin D2 increment of mushrooms after UV-B contrasted with UV-C $[17,18]$. In Korea, Pleurotus eryngii is being produced on an industrial scale on sawdust acquired from different wood sources. Other procedures have been widely investigated to reduce production costs, increase quantity and quality and make the whole process more ecofriendly and generate less waste. Of these options, mushroom production by using farming wastes/by-products, for example, cheese whey for Ganoderma lucidum, ginseng by-products for Phellinus linteus and
Lentinus edodes, citrus juice extraction waste for Corious versicolor, and green tea waste for Fomitopsis pinicola have been used [19]. The increasing tendency towards a more proficient use of agro-industrial products, for example, cassava bagasse, sugar cane bagasse, sugar beet mash, coffee mash/husk, apple pulp etc. is growing fast [20]. Button mushroom specifically Agaricus bisporus and Agaricus bitorquis are the biggest among developed edible mushroom throughout the world regardless of the different procedures of production and related yield potential or organic effectiveness. Unlike button mushroom, clam mushroom can be developed effectively over an extensive variety of areas in its common condition with no major requirement for control of temperature and other growth conditions. Shellfish mushroom, i.e., different types of Pleurotus mushroom could be developed effectively and beneficially on locally accessible Agro-cellulosic wastes with high return potential or natural proficiency [21]. Wheat straw is the primary substrate for oyster mushroom cultivation, although sufficient production can be accomplished through utilization of wheat straw with the use of supplements that considerably increment the yield per unit area and weight of wheat straw [22]. Sunflower (Helianthus annus) seed hulls are an easily available and nutrient rich substrate for growing Pleurotus ostreatus [23]. Sunflower seed hulls contain proteins, lipids and starches like those in different substrates usually utilized for Pleurotus ostreatus development [24]. The spent manure of mushroom Pleurotus pulmonarius can be used as fertilizer [25]. Among the different horticultural waste material, corn cob is a promising agricultural asset for mushroom development because of the broad development of corn and in light of the fact that corn cobs are rich in hemicelluloses [26]. Naturally, Pleurotus species live on parts of plants which are the 
poorest in supplements and vitamins. Pleurotus ostreatus is a white basidiomycete that can be effortlessly grown on an assortment of substrates, including agricultural waste [27]. For both spawn running and mushroom production improvement lignin and cellulose materials, for example, corn cobs, grain, straw, paper, wood shavings, sawdust, nutshells and vegetable wastes and industrial wastes are adequate [28]. Though wheat straw has remained the basic substrate medium for growth of Pleurotus ostreatus, less research has been conducted on identifying the effects of adding different supplements to wheat straw. This study evaluates the effects of wheat straw and brown sugar supplementation in wheat straw for growing oyster mushrooms

\section{Materials and methods}

\section{Acquiring Pleurotus ostreatus spawn}

Spawn can be regarded as the seed of a mushroom. Spawn is the starting material for mushroom production. Pleurotus ostreatus spawn was obtained from the Department of Plant Pathology, The University of
Agriculture, Peshawar and Plant Pathology Section, Agriculture Research Institute, Mingora Swat. Spawn was produced on wheat grains in a glass bottle.

\section{Substrate preparation for oyster mushroom production}

Substrates for growing Pleurotus ostreatus mushroom were made according to $[23,27]$ with some modifications. Different substrates have been used by different researchers for the production of various mushroom species. However, most of the substrates are usually of organic origin. In this study, the researcher used three different substrates for oyster mushroom production shown in (Table1). Wheat straw was used as the basal medium for incorporating two different organic amendments i.e. wheat brawn and brown sugar (Gur). Wheat straw without any amendment was used as control treatment. Gur is a source of sugar it is naturally brown in color its brown color is due to molasses. It consists of sugar crystals. It is produced by the addition of molasses to refined white sugar.

Table 1. The composition of different substrates used for oyster mushroom production

\begin{tabular}{|c|c|c|}
\hline S. No. & Substrate & Composition per bag \\
\hline $\mathbf{1}$ & Control & $1.5 \mathrm{~kg}$ wheat straw \\
\hline $\mathbf{2}$ & Wheat bran & $1.5 \mathrm{~kg}$ wheat straw $+250 \mathrm{~g}$ wheat bran \\
\hline $\mathbf{3}$ & Gur Solution & $1.5 \mathrm{~kg}$ wheat straw $+300 \mathrm{~g} / \mathrm{l}$ \\
\hline
\end{tabular}

Wheat straw was first soaked overnight in water. The next morning excess water was drained and $1.5 \mathrm{~kg}$ wheat straw (containing two different amendments) was filled in plastic bags. The bags were filled in such as way so as to fill 3/4th of bag only in order to leave some space for air and tying up.

\section{Sterilization/Autoclaving of the substrate}

Filled bags were then autoclaved at $121^{\circ} \mathrm{C}$ and 15 PSI pressure for $15 \mathrm{~min}$. After sterilization the bags were allowed to cool down before adding the spawn. The bags were opened inside a laminar flow unit and
$15 \mathrm{~g}$ spawn was added to each bag before transferring them to the growth room.

\section{Growth room/conditions/maintenance}

Inoculated bags were then transferred to the growth room. Bags were incubated at 25-30 ${ }^{\circ} \mathrm{C}$ under dark conditions till complete spawn running. For this purpose, all the windows of the growth room were covered with cardboard. Wet Ginny bags were kept on the floor to maintain relatively high humidity. Temperature of the growth room was recorded every day. Bags were also regularly monitored for spawn running and contamination by other fungi/bacteria. After 
completion of the spawn running the paper cardboards were removed from the windows as light is required for initiation of the fruiting bodies.

\section{Growth parameters}

Data were recorded on parameters such as, Number of days to half spawn running, Number of days to complete spawn running, total yield.

\section{Harvesting/Picking}

The fruiting bodies were harvested using a knife by cutting them near the end of the stipe or at the base of the fruiting body just outside the plastic bag surface and weighed using an analytical balance.

\section{Statistical analysis}

The experiment was setup in a completely randomized design (CRD). There were three treatments i.e. control containing only wheat straw (WS), wheat straw plus wheat brawn (WSB), and wheat straw plus brown sugar (WSS). Each treatment was applied in 25 replications. The data collected was statistically analyzed through Student's t-test. Error bar graph is used which is a graphical portrayal of the inconsistency of information and utilized to demonstrate the error or vulnerability in a revealed estimation. Also they give a general thought of how exact an estimation is, or then again, how a long way from the announced estimation the genuine (error free) estimation might be. Standard deviation (SD) estimates used as a measure which utilize to evaluate the extent of variation or scattering of the estimates.

\section{Results}

\section{No of days half spawn running}

The research contains three treatments e.g. control, wheat brawn and brown sugar (Gur) each with 25 replicates. In the bags containing on the wheat straw (WS), spawn running in half of the bags was completed after an average of 12.7 days. Bags supplemented with brown sugar or Gur took an average of 12.7 days to successful half spawn running. Whereas, bags containing wheat brawn took an average of 12.7 days to half spawn running (Figure 1).

No of days to complete spawn running Consistent with results of the half spawn running, the bags containing the control medium supported complete spawn running in a significantly less time as compared to the bags supplemented with either wheat brawn or brown sugar. In an average of 23.7 days, spawn running was complete in almost all the bags containing only wheat straw. On the other hand, the group of bags supplemented with wheat brawn spawn running was completed in 26 days. Whereas, spawn running was completed in 29 days in bags supplemented with brown sugar (Figure 2).

\section{Number of days to pin head formation}

Across the three treatments the bags containing the control medium (WS) took an average of 17.60 days to the formation of pin heads whereas, the bags containing medium either supplemented with wheat brawn (WSB) or brown sugar (WSS) started pin head formation after an average of 21.60 days indicating a significant delay in pin head formation (Table 2).

Number of days to start fruiting (Pin heads coming out in the form of a fruiting body) From the three treatments, formation of fruiting bodies started after an average of 19.60 days in the bags containing the control medium (WS). On the other hand, bags containing the substrate supplemented with wheat brawn (WSB) took an average of 23.60 days to start fruiting. Bags containing substrate supplemented with brown sugar (WSS) also took an average of 23.60 days to start fruiting (Table 2) indicating a significant delay in fruiting in these bags.

\section{Mushroom Picking}

Across the three groups of treatments, an average of 4 pickings with an average standard deviation of 0.5 were obtained from the control group. Group of bags supplemented with wheat brawn yielded an average of 4.16 pickings with a standard 
deviation 0.62. Bags containing substrate supplemented with brown sugar (Gur) yielded an average of 3.12 pickings with a standard deviation of 0.6 as shown in (Table 2).

\section{Mushroom Yield}

Mushroom yield was calculated for the three different treatments across the different number of pickings. From the group of bags containing only the wheat straw (control treatment), the first picking yielded an average of 248.8 grams mushroom bag ${ }^{-1}$. This yield was further increased to 304.70 grams bag ${ }^{-1}$ in the second picking and 548.53 grams bag ${ }^{-1}$ in the third picking (Table 3). Furthermore, the bags supplemented with wheat brawn yielded an average of 585.19 grams of mushroom bag ${ }^{-1}$ in the first picking, 512.44 grams bag $^{-1}$ of mushroom in the

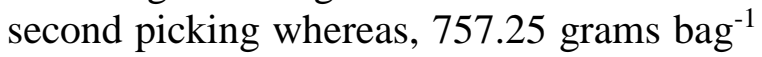
of mushroom in the third picking. Bags supplemented with brown sugar yielded an average of 253.89 grams, 190.03 and 126.17 grams bag ${ }^{-1}$ of mushroom from the $1^{\text {st }}, 2^{\text {nd }}$ and $3^{\text {rd }}$ pickings (Table 3, Figure 3). This indicated a significantly higher yield from the bags treated with wheat brawn.

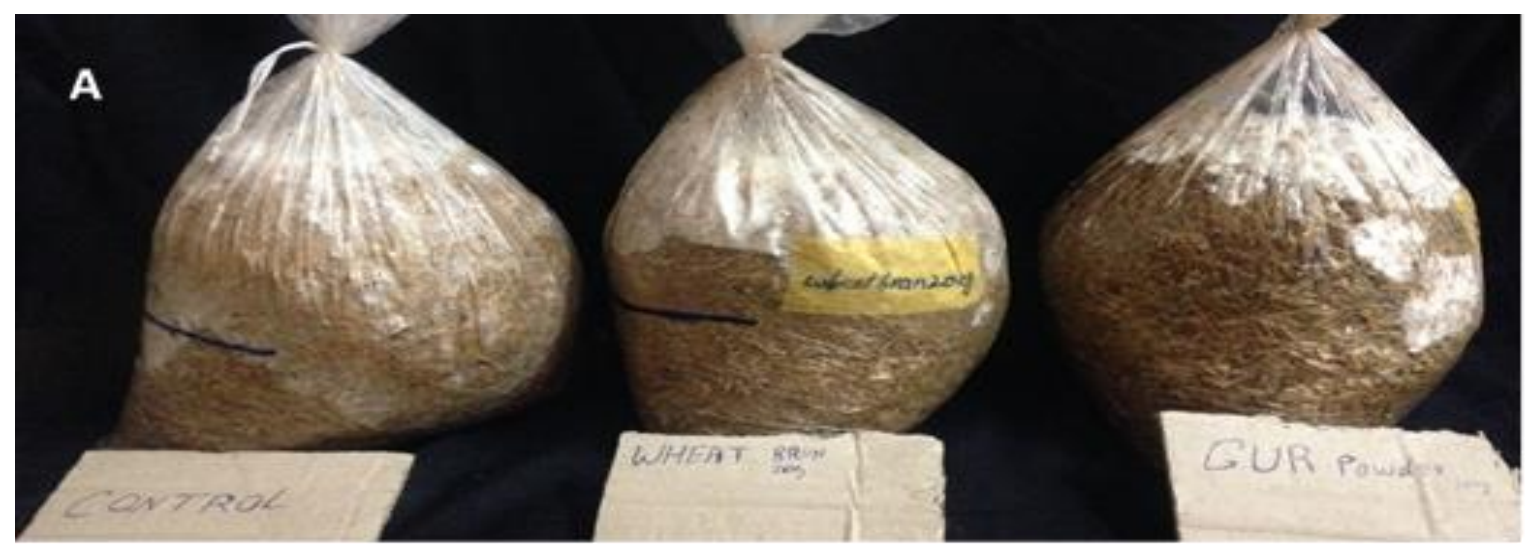

B

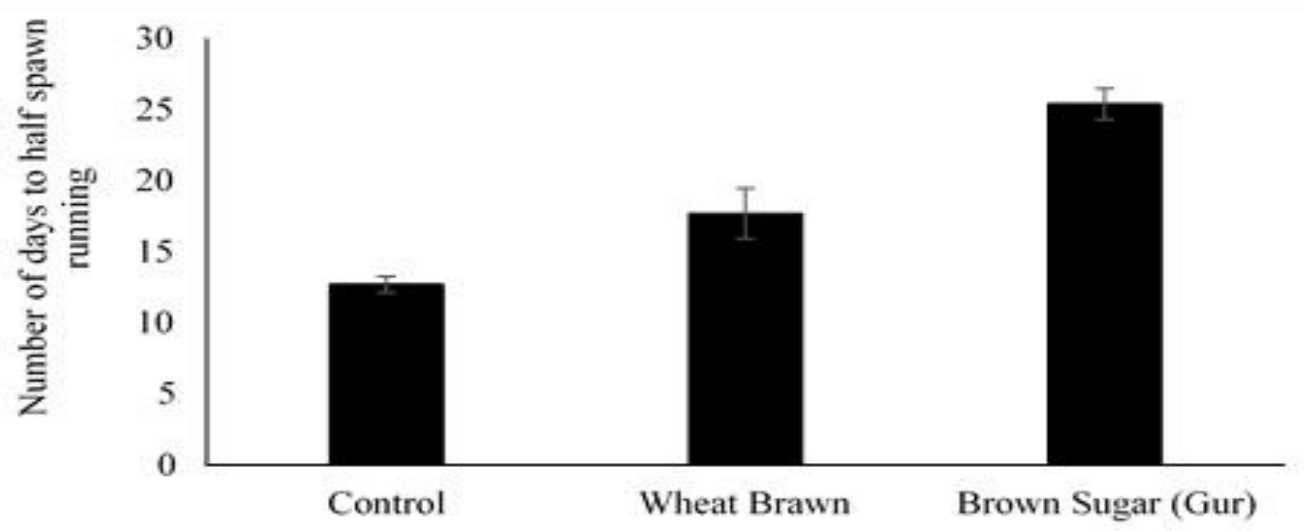

Figure 1. Number of days to half spawn running. Bags were filled leaving at least $1 / 3$ space empty and suspended for incubation (A). Bags were regularly monitored and data were recorded for the number of days to half spawn running. Half spawn running was first completed in bags supplemented with control treatment followed by bags supplemented with wheat brawn and brown sugar (B). 


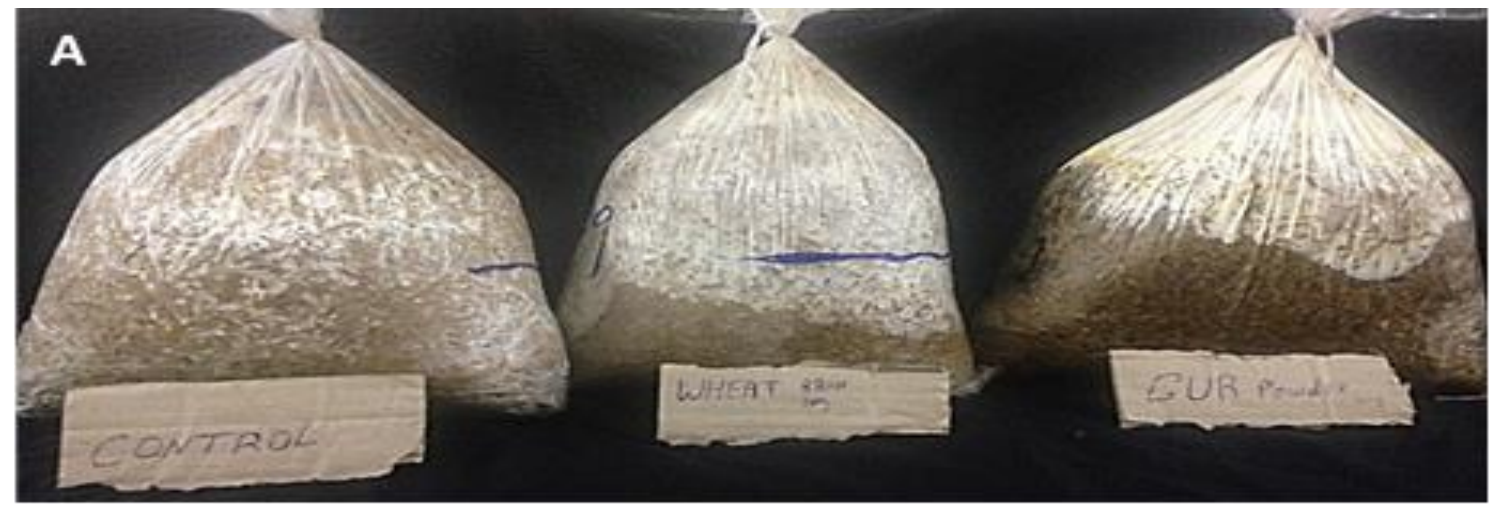

B

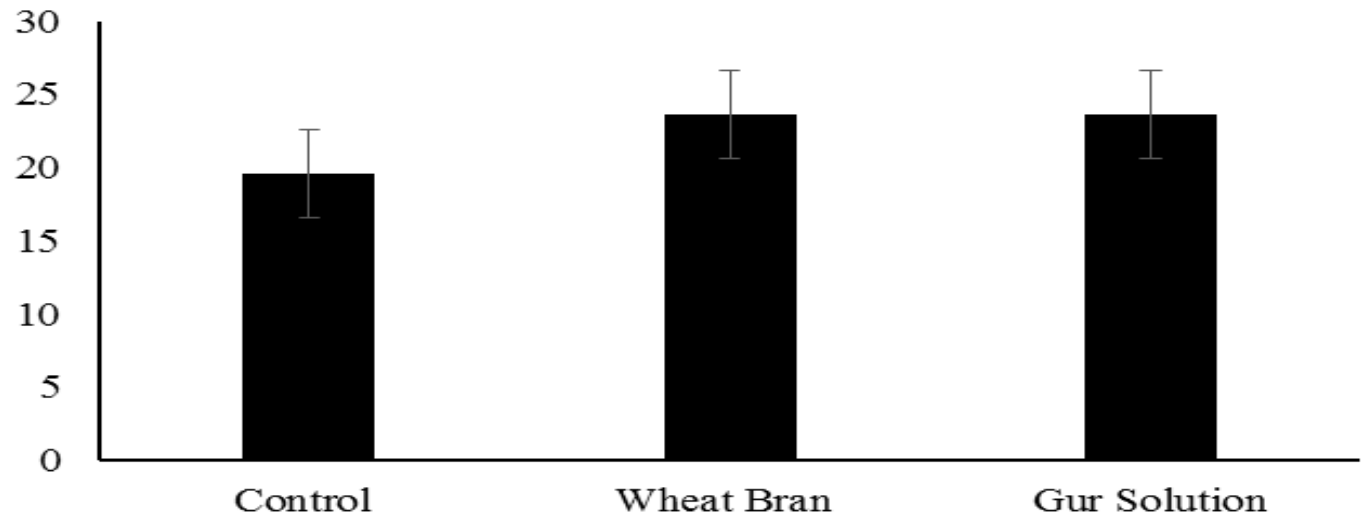

Figure 2. Number of days to complete spawn running. Bags were filled leaving at least 1/3 space empty and suspended for incubation (A). Bags were regularly monitored and data were recorded for the number of days to complete spawn running. Spawn running was first completed in bags supplemented with control treatment followed by bags supplemented with wheat brawn and brown sugar (B).

Table 2. Average number of pickings, number of days to start fruiting and number of days to pin head formation in mushrooms

\begin{tabular}{|c|c|c|c|c|c|c|c|c|c|}
\hline & \multicolumn{3}{|c|}{ Number of pickings } & \multicolumn{3}{c|}{$\begin{array}{c}\text { Number of days to start } \\
\text { fruiting }\end{array}$} & \multicolumn{3}{c|}{$\begin{array}{c}\text { Number of days to pin head } \\
\text { formation }\end{array}$} \\
\hline & Control & Wheat Bran & Gur Solution & Control & $\begin{array}{c}\text { Wheat } \\
\text { Bran }\end{array}$ & $\begin{array}{c}\text { Gur } \\
\text { Solution }\end{array}$ & Control & $\begin{array}{c}\text { Wheat } \\
\text { Bran }\end{array}$ & $\begin{array}{c}\text { Gur } \\
\text { Solution }\end{array}$ \\
\hline Average & 4.00 & 4.16 & 3.12 & 19.60 & 23.60 & 23.60 & 17.60 & 21.60 & 21.60 \\
\hline SD & 0.5 & 0.62 & 0.6 & 3.1 & 3.02 & 3.02 & 3.04 & 3.02 & 3.03 \\
\hline
\end{tabular}

Table 3. Mushroom yield (gm) obtained from different treatments across three different pickings

\begin{tabular}{|c|c|c|c|c|c|c|c|c|c|}
\hline & \multicolumn{3}{|c|}{ Control } & \multicolumn{3}{c|}{ Wheat Bran } & \multicolumn{3}{c|}{ Gur Solution } \\
\hline & 1st pick & $\mathbf{2}^{\text {nd }}$ pick & $\mathbf{3}^{\text {rd }}$ pick & 1st pick & $\mathbf{2}^{\text {nd }}$ pick & $\mathbf{3}^{\text {rd }}$ pick & 1st pick & $\mathbf{2}^{\text {nd }}$ pick & $\mathbf{3}^{\text {rd }}$ pick \\
\hline Average & 248.88 & 304.70 & 548.53 & 585.19 & 512.44 & 757.25 & 253.89 & 190.03 & 126.17 \\
\hline SD & 36.64 & 39.31 & 28.63 & 33.88 & 11.04 & 8.06 & 23.43 & 10.10 & 28.63 \\
\hline
\end{tabular}




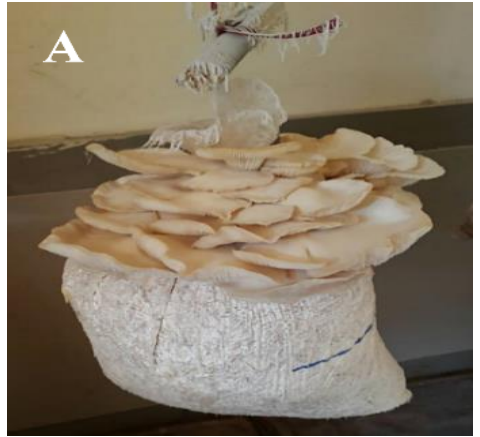

Control

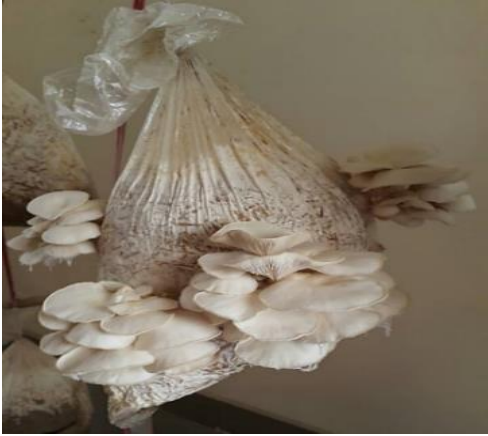

Wheat

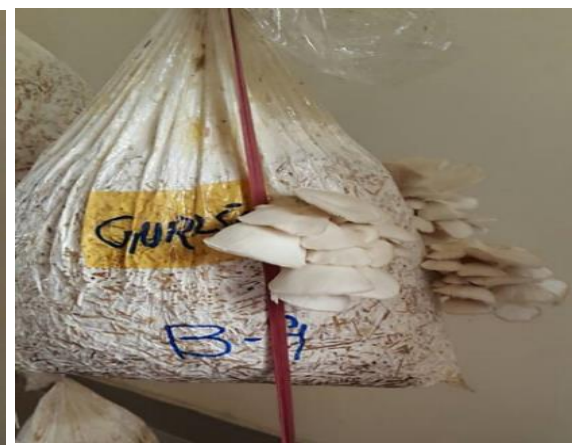

Brown

B

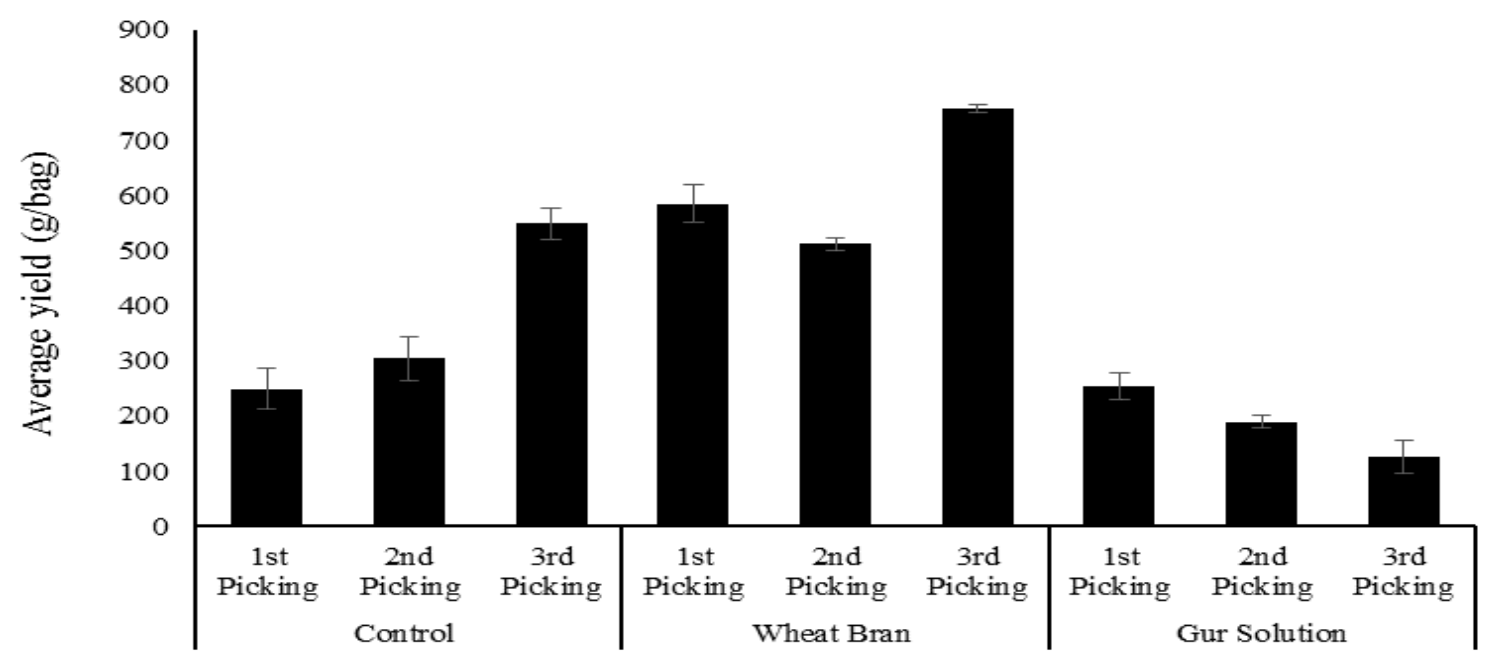

Figure 3. Mushroom yield obtained from the different treatments across two separate pickings. Bags were filled leaving at least $1 / 3$ space empty and suspended for incubation (A). Bags were regularly monitored and data were recorded average mushroom yield. Maximum yield was provided by bags containing with wheat brawn following by bags containing only wheat straw and bags supplemented with brown sugar or Gur solution (B).

\section{Discussion}

Overall the results indicated a significant effect of the treatments on the yield and yield parameters of Pleurotus ostreatus. Initially the number of replicates per treatment was set to 30 . However, an average of 5 replicates were lost attributed to infections caused due toopen air inoculation of substrate bags with spawn and subsequent poor growth conditions. This corroborates with the findings of [29] who recommended chemical sterilization over heat sterilization. Following heat or steam sterilization of substrate bags in the autoclave, the bags are taken out and allowed to cool down up to around $40^{\circ} \mathrm{C}$. Later, the bags are usually inoculated with spawn outside a laminar air flow unit in open air allowing microbes to enter the bags that later cause infection in the substrate. Contamination by fungi such as Rhizopusspp, Pennicilliumspp and Aspergillus spp are most commonly observed in such cases. Furthermore, as described earlier, facilities required for maintenance of temperature and moisture were not available and the temperature increased up to more than $37^{\circ} \mathrm{C}$ after the first two weeks of incubation. Furthermore, brown sugar being a rich source 
of sugar/carbohydrates or carbon resulted in fermentation and liquidity in the substrate in some bags. As a result, wheat straw rotted, giving a foul smell in some of the bags containing brown sugar. This is the reason why [30] recommended utilization of carbohydrate or carbon source for the production of spawn rather than in mushroom substrate. They added "dextrose" as carbohydrate/carbon source in PDA medium in order to grown P. ostreatus for addition to wheat straw substrate as spawn. Despite careful sterilization and handling, some bags containing wheat brawn were also contaminated with fungi such as Penicillium spp. and Aspergillus spp. However, as described in the results section bags supplemented with wheat brawn and brown sugar were slow in spawn running but sustained the production of fruiting bodies for a longer period of time as compared to control bags. The three treatments i.e. control, wheat brawn and brown sugar (Gur) gave a maximum of four pickings. Several published papers report up to 4 or 5 pickings. Spawn running was completed in almost $80 \%$ of the bags containing only wheat straw after 25 days of incubation. However, spawn running was slow in the bags containing wheat brawn and brown sugar shown in (Figures 1 and 2). This may be due to the fact that control bags contained only wheat straw as a single food substrate making it easy for the mycelia to penetrate and invade quickly. On the other hands, bags containing either wheat brawn or brown sugar represented a more complex and diverse food medium making it difficult for the mycelium to colonize. That's why these bags started pin head formation and fruiting body formation significantly later than control bags. This facilitated the production of mushrooms for a longer period of time in these bags. [31] also obtained a significantly higher yield and sustained production of Pleurotus ostreatus and Pleurotus florida with significant bioactive compounds when grown on saw dust which is a highly complex substrate as compared to corn cobs. [32] also obtained significantly different effects of different substrate supplements on colonization period, biological efficiency, fruiting body characteristics, total yield and nutritional composition Pleurotus ostreatus and Pleurotus cytiodiosus indicating the importance of substrate types in the quantity and quality of the final mushroom product. Interestingly, the average yield obtained for $P$. ostreatus in these studies was relatively higher than that achieved in this study which may be due to one of the following reasons. In these studies, spawn was added to the substrate in a much higher quantity and multiple locations within a single substrate container allowing better and faster penetration and spawn running with a much higher inoculum titer to begin with. Furthermore, the substrate container was placed horizontally after inoculation at controlled temperature and moisture conditions. Contrastingly, in this study the bags were inoculated with a small quantity of inoculum (spawn) only once at the top of the substrate and the bags were then tied up vertically resulting in high compaction of the substrate. Results showed that the bags containing the control substrate achieved half spawn running in an average of 12 days as compared to 18 days in bags containing substrate supplemented with wheat brawn and 25 days in bags containing brown sugar shown in (Figure 1). Pleurotus ostreatus mycelium spread across half of the bag within 12 days on control medium. However, only about $15 \%$ of the bags were covered by the mycelium on substrate supplemented with wheat brawn and brown sugar. From these results it is clear that bags containing either wheat brawn or brown sugar showed a significantly slow response in spawn running. The final average yield of mushroom was calculated for three different 
pickings for each of the treatment. Results showed a significantly higher average mushroom yield from bags supplemented with wheat brawn sustained over a much longer period of time. This is parallel to the findings of the [31] who obtained significantly higher yield Pleurotus ostreatus for a longer period of time when grown on saw dust which like wheat brawn; is a chemically complex substrate compared to only wheat straw. Mushroom being a highly nutritious food commodity has a much smaller shelf life therefore, a sustained production of mushroom for a longer period of time provides an opportunity of obtaining fresh mushrooms over a longer duration suggested high suitability of wheat brawn for growing Pleurotus ostreatus mushroom at house hold and farm level. It is further recommended totestthe effects of other different doses of wheat brawn and brown sugar on Pleurotus ostreatus yield. Beside this, it is also important to test other sources of starch and sugar as supplements in the substrate.

\section{Authors' contributions}

Conceived and designed the experiments: $M$ Sajid, M Imtiaz \& A Hussain, Performed the experiments: M Sajid, H Ullah \& A Hussain, Analyzed the data: MA Khan, S Hussain \& F Jalal, Contributed materials/ analysis/ tools: B Islam \& F Said, Wrote the paper: M Sajid, A Hussain, M Imtiaz \& F Jalal.

\section{References}

1. Hibbett DS, Binder M, Bischoff JF, Blackwell M, Cannon PF, Eriksson OE, Huhndorf S, James T, Kirk PM, Lucking R, Lumbsch HT \& Lutzoni F et al. (2007). A higher-level phylogenetic classification of the Fungi. Mycological Res 111: 509-547.

2. Ammirati, JF, Traquair JA \& Horgen PA (1985). Poisonous mushrooms of the northern United States and Canada. Minneapolis, University of Minnesota Press.

3. Dickinson CH \& Lucas JA (1982). VNR color dictionary of mushrooms. New York, Van Nostrand Reinhold.
4. Chang R (1996). Functional properties of edible mushrooms. Nutrition Reviews 54(11): S91-S93.

5. Smith J, Rowan N \& Sullivan R (2002). Medicinal Mushrooms: Their therapeutic properties and current medical usage with special emphasis on cancer treatments. Http. Sci. Cancer Research UK. org/labs/med_mush/final_pdfs/chapt3a. pdfH.

6. Foschia M, Peressini D, Sensidoni A \& Brennan CS (2013). The effects of dietary fibre addition on the quality of common cereal products. J Cere Sci 58(2): 216-227.

7. Nanba H (1993). Maitake mushroom the king mushroom. Mush News 41(2): 22-25.

8. Brown GD (2006). Dectin-1: a signalling non-TLR pattern-recognition receptor. $N R$ Imm 6(1): 33-43.

9. Kerrigan RW (2005). Agaricus subrufescens, a cultivated edible and medicinal mushroom, and its synonyms. Myco 97(1): 12-24.

10. Devece C, Rodriguez-Lopez JN, Fenoll LG, Tudela J, Catala JM, de los Reyes E\& Garcia-Canovas F (1999). Enzyme inactivation analysis for industrial blanching applications: Comparison of microwave, conventional, and combination heat treatments on mushroom polyphenoloxidase activity. J Agri and Food Chem 47(11): 4506-4511.

11. Akram K \& Kwon JH (2010). Food Irradiation for Mushrooms: A Review. $J$ of the Korean Society for App Bio Chem 53(3): 257-265.

12. Beaulieu M,D'Aprano $G$ \& Lacroix $M$ (2002). Effect of dose rate of gamma irradiation on biochemical quality and browning of mushrooms Agaricus bisporus. Rad Phys and Chem 63(3-6): 311-315.

13. Tano K, Arul J, Doyon G \& Castaigne F (1999). Atmospheric composition and quality of fresh mushrooms in modified atmosphere packages as affected by storage temperature abuse. J Food Sci 64(6): 10731077.

14. Farber J, Harris L, Parish M, Beuchat L, Suslow T, Gorney J, Garrett E \& Busta F (2003). Microbiological safety of controlled and modified atmosphere packaging of fresh 
and fresh-cut produce. Compr Rev in Food Sci and Food Safety 2(S1): 142-160.

15. Penney N \& Bell RG (1993). Effect of Residual Oxygen on the Color, Odor and Taste of Carbon-Dioxide-Packaged Beef, Lamb and Pork during Short-Term Storage at Chill Temperatures. Meat Sci 33(2): 245252.

16. Briones GL, Varoquaux P, Chambroy y,Bouquant J, Bureau G \&Pascat B (1992). Storage of Common Mushroom under Controlled Atmospheres. Int J Food Sci and Tech 27(5): 493-505.

17. Teichmann A, Dutta PC, Staffas A \& Jägerstad M (2007). Sterol and vitamin D 2 concentrations in cultivated and wild grown mushrooms: effects of UV irradiation. $L W T$ Food Sci and Tech 40(5): 815-822.

18. Khan ZU, Jiayin L, Khan NM, Mou W, Li D, Wang Y, Feng S, Luo Z, Mao L\& Ying T (2016). Suppression of cell wall degrading enzymes and their encoding genes in button mushrooms (Agaricus bisporus) by $\mathrm{CaCl}_{2}$ and citric acid. Plant Foods for Human Nut $1-6$.

19. Pourbafrani M, Forgács G, Horváth IS, Niklasson C \& Taherzadeh MJ (2010). Production of biofuels, limonene and pectin from citrus wastes. Bio tech 101(11): 42464250.

20. Pandey A, Nigam P \& Vogel M (1988). Simultaneous saccharification and protein enrichment fermentation of sugar-beet pulp. Biotechnology Letters 10(1): 67-72.

21. Basak MK, Chanda S, Bhaduri SK, Mondal SB \& Nandi R (1996). Recycling of jute waste for edible mushroom production. Industrial Crops and Products 5(3): 173176.

22. Chang S, Lau O \& Cho K (1981). The cultivation and nutritional value of Pleurotus sajorcaju. Applied Micro and Biotech 12(1): 58-62.

23. Darjania L, Curvetto N, Schapiro M, Figlas D \& Curvetto D (1997). Sunflower seed hulls as a substrate for cultivation of
Pleurotusostreatus. Mushroom NewsKennett Square 45: 6-11.

24. Cancalon P (1971). Chemical composition of sunflower seed hulls. $J$ of the American Oil Chemists' Society 48(10): 629.

25. Chiu SW, Law SC, Ching ML, Cheung KW \& Chen MJ (2000). Themes for mushroom exploitation in the 21st century: Sustainability, waste management, and conservation. $J$ of General and Appl Micro 46(6): 269-282.

26. Tada K, KannoT \& Horiuchi JI (2012). Enhanced production of bioxylitol from corn cobs by Candida magnoliae. Industrial \& Engineering Chem Res 51(30): 1000810014.

27. Hadar Y, Kerem Z, Gorodecki B \& Ardon O (1992). Utilization of lignocellulosic waste by the edible mushroom, Pleurotus. Biodegradation 3(2-3): 189-205.

28. Baysal E, Peker H, Yalinkiliç MK \&Temiz A (2003). Cultivation of oyster mushroom on waste paper with some added supplementary materials. Biores Tech 89(1): 95-97.

29. Roksana KM, Ahmed KU \& Uddin MN (2018). Effect of Chemically Disinfected Wheat Straw on the Growth and Yield of Pleurotus ostreatus Mushroom. J of Agric Studies 6: 189-202.

30. Memon AA, Mangrio GS, Kaleri AA, Kumar B \& Khan M (2017). Effect of Dextrose Sugar on the Growth and Production of Oyster Mushroom (Pleurotus ostreatus) through Tissue Culture. J of Basic and Applied Sci 13: 139-142.

31. Kinge $\mathrm{T}$, Adi $\mathrm{E}$, Mih $\mathrm{A}$, Ache $\mathrm{N} \& \mathrm{Nji} \mathrm{T}$ (2016). Effect of substrate on the growth, nutritional and bioactive components of Pleurotus ostreatus and Pleurotus florida. African J of Biotechnol 15: 1476-1486.

32. Hoa HT, Wang CL \&Wang CH (2015). The effects of different substrates on the growth, yield, and nutritional composition of two oyster mushrooms (Pleurotus ostreatus and Pleurotus cystidiosus). Mycobio 43: 423434. 